\title{
Rumination, Substance Use and Self-harm in a Representative Australian Adult Sample
}

Running title: Rumination, Substance Use and Self-harm

Robert J. Tait $^{\text {a, b, e }}$, Jay Brinker ${ }^{c}$, Carl I. Moller ${ }^{\text {b, d }}$, Davina J. French ${ }^{\text {a }}$

${ }^{a}$ Centre for Research on Ageing, Health and Wellbeing, Australian National University, Canberra ACT 0200, Australia

${ }^{\mathrm{b}}$ Centre for Mental Health Research, Australian National University, Canberra ACT 0200, Australia

${ }^{c}$ Department of Psychology, Australian National University, Canberra ACT 0200, Australia

${ }^{\mathrm{d}}$ Melbourne School of Psychological Sciences, The University of Melbourne, Melbourne, Victoria 3010, Australia

${ }^{\mathrm{e}}$ National Drug Research Institute, Curtin University, Perth Western Australia

Declaration of interest The PATH study was supported by an NHMRC Program Grant 179805 and NHMRC Project Grant 157125. The sponsors had no role in the design, conduct or reporting of the research.

Corresponding Author: Robert J. Tait

National Drug Research Institute

GPO Box U1987

Perth WA 6845

Telephone: +61 89266 1600: Fax: +61 89266 1611: Email: Robert.Tait@curtin.edu.au

Keywords: self-harm, depression, rumination, substance, longitudinal, adult 


\begin{abstract}
Background: There are few data on self-harm in the general population, especially examining the roles of rumination and substance use. Objectives: To evaluate the inter-relationships of rumination, self-harm and potential mediating variables. Method: A cohort with follow-up every four years involving a random sample of adults aged 20-24 and 40-44 years (at baseline) living in Australia. The survey included items on three common forms of self-harm. Other measures included rumination, Goldberg Anxiety and Depression scales, substance use, coping style (Brief COPE) and demographic risk factors. Results: The sample comprised 2184 women and 1942 men with 287 self-harm cases (7.0\%). Depression and coping style were significant mediators of rumination on self-harm for men, with depression being the only robust mediator for women. For males age and education were also significantly associated while for women, age, smoking, trauma and sexual abuse were significant. Conclusions: Men and women differ on mediators of selfharm.
\end{abstract}




\section{$\underline{\text { Introduction }}$}

The first report of self-harm behaviour in the literature was probably in the fifth century BC, when Sophocles depicted Oedipus gouging his eyes out in reaction to unwittingly sleeping with his mother: similar behaviours are still occasionally reported, primarily among patients with psychosis (Kratofil, Baberg, \& Dimsdale, 1996). However, self-harm more generally manifests as directly damaging tissue, for example by cutting or burning, or indirect harm such as starving or binge eating, with socially sanctioned behaviours excluded from these definitions (Feldman, 1988; Fliege, Lee, Grimm, \& Klapp, 2009; Moller, Tait, \& Byrne, 2012a). Research exploring what compels a person to engage in such dramatic, dangerous and possibly fatal behaviours has identified a number of possibilities. Functions of self-harm include, anti-dissociation (i.e. "to feel something"), anti-suicide, to establish interpersonal boundaries, interpersonal influence, selfpunishment, sensation seeking and as a strategy to regulate one's emotions (Klonsky, 2007; Suyemoto, 1998).

Emotion or affect regulation refers to the processes by which emotions are managed, altered or avoided (Gross, 1999). The mechanism by which self-harm helps to regulate emotion is not clear, however one possible explanation may be attentional deployment (Gratz, 2003; Gross, 1999). Self-harm acts, such as cutting one's skin with a blade, very effectively direct attention away from the emotion and toward the act of self-harm. These behaviours may also direct attention away from the negative and distressing thoughts that co-occur with the emotions. The thoughts associated with negative emotions, particularly if they are ruminative in nature, can exacerbate the emotions.

Rumination has been proposed as another emotion regulation strategy due to the perception that it fosters understanding and solution generation (Aldao \& Nolen-Hoeksema, 2012). Research shows that it is actually a maladaptive strategy, paradoxically increasing mood lability, worsening depressive symptoms, and prolonging depressive episodes (Brinker \& Dozois, 2009). This repetitive, uncontrollable focus on the self increases the salience of any potential negative content. 
Heatherton and Baumeister (1991) argued that individuals engage in binge eating, a type of self harm, as a way to escape from the aversive self-awareness brought about by ruminating. This illustrates the potential vicious cycle generated by these behaviours - ruminating exacerbates negative mood and self-focus, self-harm regulates the overwhelming emotion, the individual feels ashamed about self-harming and begins ruminating about the behaviour and the shame. What is most striking is that both behaviours are failed attempts to regulate emotions, and both inadvertently worsen the emotional experience.

This cyclical nature is also demonstrated in the emotional reaction to the self-harm behaviour itself. Subsequent guilt or shame concerning the self-harm may precipitate an emotional cascade with further negative emotions leading to more self-harm (Selby, Anestis, \& Joiner, 2008). Rumination may further exacerbate this situation. Ruminating involves a repetitive, recurrent style of thinking about one's mood and the possible causes and consequences of that mood. Self-harm may provide initial relief of unwanted negative emotions, however the ensuing guilt or shame mentioned above would be further worsened by brooding and reflecting on the act and the negative emotions stemming from it. This cascade would be intensified due to the attention and focus provided by a ruminative response style.

While substance use has been considered a result of failed emotion regulation (Axelrod, Perepletchikova, Holtzman, \& Sinha, 2011) it is seldom considered as an emotion regulation strategy in its own right. However the idea of self medication as an explanation for substance use in mental health disorders supports the argument that people may use various substances to reduce their anxiety, to cope with anger and frustration and to alleviate sad or depressed mood (Khantzian, 1997). Thus, like rumination and self-harm, individuals may engage in substance use and abuse as a means to regulate their emotional experiences.

The objective of this study was to examine the relationship between these forms of emotion regulation; rumination, substance use and self-harm together with the potentially mediating role of mood (i.e. depression and anxiety). An earlier exploration of rumination, depression and substance 
use as a coping mechanism reported gender differences, with substance use as a coping mechanism a significant predictor for men but not women (Nolen-Hoeksema \& Harrell, 2002). Currently, the majority of data on these variables come from adolescent or university samples, with few from the general population. A notable exception was a large Australia general population study which found strong associations between various licit and illicit substances and self-harm (odds ratios OR 2.88 - 6.52) but did not simultaneously examine behavioural, cognitive and other risk factors (Martin, Swannell, Hazell, Harrison, \& Taylor, 2010). Based on previous literature, it is expected that these three emotion regulation strategies will be significantly related. Further, the longitudinal exploration will demonstrate that rumination and substance use account for unique variance in future self-harm behaviours. This is in no way intended to imply causation, simply to demonstrate a prospective relationship between these behaviours, which may simply capture a segment of a cyclical phenomenon.

\section{Method}

The data were drawn from the Personality and Total Health (PATH) Through Life project. This is a large scale survey of the health and well-being of adults living in the Australian Capital Territory (ACT) and the nearby town of Queanbeyan, New South Wales. The original focus of PATH was to examine the inter-relationships between the domains of depression and anxiety, substance use, and, cognitive ability and dementia (Anstey et al., 2011). Recruitment to wave 1 was conducted in 1999-2002, with follow-up every four years: wave 2 data were collected in 2003-2006 and wave 3 data in 2007-2010. This study used data from wave 2 and wave 3.

\section{Participants}

The study is comprised of three age cohorts; aged 20-24 (20s, n=2404), 40-44 (40s, n=2530) and 60-64 years $(60 \mathrm{~s}, \mathrm{n}=2551)$ at baseline. The participants were randomly drawn from the electoral rolls of the ACT and Queanbeyan. Only the 20s and 40s are relevant to the current study as the 60s were not asked about their use of illicit drugs. A comparison of the PATH data and the relevant 2001 Australian Census data showed that there were no significant differences on key 
demographic characteristics (e.g. marital and employment status) suggesting that the PATH cohorts are representative of the ACT and Queanbeyan population (Fairweather, Anstey, Rodgers, Jorm, \& Christensen, 2007). However, a significantly greater proportion of those lost to follow-up by wave 2 were male, from the 20's cohort, had never married or were other than in full time employment at wave 1.

\section{Procedure}

We wrote to a random selection of potential participants drawn from the electoral roll. This was followed by a telephone call. Subsequently, assessments were conducted at a location convenient for participants, generally in their home or at the Australian National University. The survey was self-completed on a palmtop personal computer with an interviewer present to provide assistance if required. At subsequent waves, we attempted to contact participants via the telephone, e-mail or by visiting their last known address. Further information was sought from secondary contacts, the electronic telephone database and the electoral roll. For participants no longer in the vicinity, we arranged in-person interviews whenever possible but participants overseas were asked to complete a postal/email survey. The study was approved by the Australian National University Human Research Ethics Committee.

\section{Measures}

Rumination was quantified with a 10 -item version of the 22 -item Rumination Responses Scale (RRS) (Nolen-Hoeksema \& Morrow, 1991). The shortened version is highly correlated ( $\mathrm{r}=.93$ ) with the 22-item RRS, has good internal reliability (alpha=.87) (personal correspondence S NolenHoeksema 1998) and has been used previously with young adults (Davis \& Nolen-Hoeksema, 2000).

Substance use was assessed from various measures. The Brief COPE (added at wave 3) contains 14 sub-scales (Carver, 1997) including the two-item Substance (COPE-S) scale ('I've been using alcohol or other drugs to make myself feel better", "I've been using alcohol or other drugs to help me get through it”) which had a correlation of Spearman's rho $=0.91$ demonstrating 
strong reliability. In addition, alcohol use was assessed with the World Health Organization Alcohol Use Disorders Identification Test (AUDIT) (Babor, Higgins-Biddle, Saunders, \& Monteriro, 2001). AUDIT scores range from 0 to 40 . A score $\geq 8$ is generally accepted as indicating risky or hazardous drinking (Meneses-Gaya, Zuardi, Loureiro, \& Crippa, 2009). Smoking status was categorized as never, former or current smoker. Cannabis use was classified as never, former or currently use.

The self-harm questions were added to PATH at wave 3 and asked: "In the last year, have you ever done any of the following to deliberately hurt yourself: Taken an overdose of medication; Cut yourself; Banged your head or fist against something). The 'overdosing' and 'cutting' behaviours reflect methods of self-harm listed by the International Classification of Diseases, Ninth Revision (World Health Organization, 1986) (i.e. E950 self-inflicted poisoning by solid or liquid substances, E956, self-inflicted injury by cutting and piercing). The 'banging' item was derived from a selfharm interview for use with a population based sample of adults (Nada-Raja, Skegg, Langley, Morrison, \& Sowerby, 2004). A binary variable was created to indicate whether each participant had engaged in any form of self-harm in the past year.

Depression and anxiety are associated with rumination (Aldao, Nolen-Hoeksema, \& Schweizer, 2010) and were assessed with the Goldberg Depression and Anxiety Scales (Goldberg, Bridges, Duncan-Jones, \& Grayson, 1988). In the current study at wave 3, alpha $=0.90$ and 0.88 at wave 2 .

The demographic information collected included age, gender, marital status, employment situation, education (coded as secondary, trade certificate, diploma, undergraduate degree, higher degree), items assessing eight major lifetime traumas adapted from the CIDI post-traumatic stress disorder module (World Health Organization, 1993) and childhood sexual abuse. This last question was from the Childhood Adversity Scale which contains items from existing scales and items developed from open ended responses in an earlier study (Rosenman \& Rodgers, 2004). The measure has subsequently been used in clinical and general samples (Clark, Caldwell, Power, \& 
Stansfeld, 2010; Moore, Green, \& Carr, 2012). These control variables were selected following a review of risk factors for self-harm, which identified a range of factors including (younger) age, unemployment, lack of a partner and traumatic childhood experiences and sexual abuse (Fliege et al., 2009). The same review also noted that there were no studies of self-harm and education level or socio-economic status in adults.

\section{Analysis}

Initial between groups comparisons of any versus no self-harm participants were made with chi-square for differences in proportions and t-tests or Mann Whitney $U$ for continuous variables that were not normally distributed. The maximum value for $U$ is the product of the two groups and the value of $U$ for no difference in ranks is the product divided by 2. Cross panel lagging was used to determine the relationship between rumination and depression as independent or mediating variables in predicting self-harm. The mediation analyses were conducted separately for males and females with the SPSS macro Indirect (Hayes, 2012; Preacher \& Hayes, 2008). Indirect calculates the four mediation steps specified by Baron and Kenny (1986). These are to show: 1) a significant correlation between the initial and the target variables (c path: see figure 1a for example), 2) that the initial variable is correlated with the potential mediators (a path), 3) that the mediators are correlated with the outcome variable (b path) after controlling for the initial variable and 4) to establish full mediation, that the initial variable and outcome should no longer be significantly correlated when the mediators are added (notated as the c' path). We also calculated 1000 iteration bias-corrected bootstrap confidence intervals $(\mathrm{CI})$. Bootstrapping creates an empirical estimation of the CI and does not rely on the potentially invalid assumption that the sample distribution is approximately normal (Preacher \& Hayes, 2008). The binary outcome variable was any self-harm. Goldberg depression, Goldberg anxiety, COPE-S scores and AUDIT scores were modelled as mediators. Control variables were then added to the models in the order 1) age group, 2) cannabis, 3) tobacco, 4) education and financial strain, 5) lifetime trauma and childhood sexual abuse. The COPE-S measure was added to the PATH study at wave 3, so neither this nor the measures of 
anxiety and depression were included as wave 2 control variables. Indirect calculates the indirect effects of a putative causal variable on an outcome via one or more mediator variables simultaneously whilst controlling for additional variables. Indirect estimates path values with logistic regression where the outcome is binary: mediators must be continuous variables but controls can be continuous or dichotomous. Thus cannabis and tobacco status were coded as never versus ever (i.e. current + former) users. Nagelkerke's $r^{2}$ provides a logistic alternative to $r^{2}$ in linear regression, with higher values showing a stronger relationship between the predictors and the prediction. Indirect produces unstandardized path coefficients: standardized values were estimated by repeating the analyses using standardized variables as recommended (Hayes, 2013).

\section{$\underline{\text { Results }}$}

We collected data from 4,160 participants at wave 3 . Of these 1,978 were in the 20 s cohort ( $82.3 \%$ follow-up from wave 1 ) and 2,182 were in the 40 s cohort (86.3\% of wave 1$)$. Self-harm data were respectively available from 1954 and 2172 people, who constituted the study cohort $(n=4126,99 \%)$. The prevalence of self-harm in the 20's cohort was $10.5 \%$ (95\% confidence interval (CI) 9.1-11.9\%, $\mathrm{n}=206)$ and 3.7\% (95\% CI 2.9-4.5\%, $\mathrm{n}=81)$ in the 40's cohort. In total it was reported by $7.0 \%$ (95\% CI 6.2-7.8\%, n=287) of participants. As shown in Table 1, those who had ever self-harmed differed from those who had never self-harmed on a range of characteristics.

\section{Table 1}

Table 2 shows the correlations between wave 2 and wave 3 measures of alcohol, substance use as a coping mechanism, depression and anxiety separately for males and females. Given the large sample size, all but two correlations were significant at $p<.001$, but only the wave 3 depression and anxiety correlation for both genders $(50.4 \%)$, the wave 2 depression and anxiety correlation for both genders $(54.8 \%)$ and the wave 3 AUDIT and wave 2 AUDIT correlation for males (57.8\%) had greater than $50 \%$ of variance in common. Using Fisher's $r$ to $z$ transformation to assess differences between two correlation coefficients, five pairs of correlations showed significant gender differences (e.g. between wave 3 COPE-S and wave 2 AUDIT). Cross-lagged 
panel analysis showed that the regression coefficient was greater for wave 2 rumination (B .223) on wave 3 depression controlling for wave 2 depression than wave 2 depression (B .134) on wave 3 rumination controlling for wave 2 rumination. This provided justification for developing models using rumination as the initiating variable and depression, anxiety, alcohol use and coping as potential mediators.

\section{Table 2}

Initial analyses examined depression, anxiety, alcohol use and coping by using substances as mediating variables between rumination and self-harm separately for males and females. Anxiety did not meet the criteria for a mediator ( $b$ path not significant) for men, and was thus used as a control rather than mediating variable in the male final model. For women, the model including the COPE-S had a better fit (Nagelkerke 16\%) than the model using the alcohol variable (13\%). For males, the two models had similar fit statistics (Nagelkerke 16\%), so the COPE-S was used to match the female model.

Figure 1a shows the final model for males with both the COPE-S and depression measures fulfilling the criteria as mediators. The significant controls were (younger) age group and increasing education. Overall Nagelkerke's $r^{2}$ was $22 \%$. Among females (figure 1b), both depression and COPE-S were significant mediators, but the anxiety measure no longer fulfilled the criteria after the inclusion of lifetime trauma and childhood sexual abuse as controls. In the full model (younger) age group, ever smoked, increasing number of traumas and having suffered childhood sexual abuse were significant controls (Nagelkerke's $\mathrm{r}^{2} 21 \%$ ).

\section{Figure $1 a \& 1 b$}

Table 3 shows the bias-corrected confidence intervals for the mediators confirming the above analyses for males, with depression $(z=3.66, p<.001)$ and substance use as a coping mechanism $(z$ $=2.28, p=.023$ ) accounting for a significant proportion of the variance after controlling for all other variables. The pairwise contrasts allow the size of the indirect effects to be compared: 
depression has a significantly larger effect than substance use as a coping mechanism (95\% CI .004, .027). For females, depression $(z=2.56, p=.01)$ accounted for a significant proportion of the variance after controlling for other variables but substance use as a coping mechanism $(z=$ 2.08, $p=.038$ ) did not replicate in the bootstrap analysis (95\% CI -.001, .012). The pairwise contrasts showed that the measures of depression, anxiety and the COPE-S did not differ significantly in the proportion of variance they explained.

Table 3

\section{$\underline{\text { Discussion }}$}

Self-harm was prevalent in this general population sample of adults, with seven percent reporting engaging in the behaviour in the last year. Those who engaged in self-harm differed on a range of demographic and substance use variables from those who did not self-harm. A ruminative response style was associated with self-harm and this was mediated by measures of depression and substance use as a coping mechanism. However, as previously noted, there were gender differences in substance use as a coping mechanism (Nolen-Hoeksema, 2004). There were also differences in the other mediating variables and significant covariates for men and women. While gender differences were not the primary focus of this paper, it may be prudent to explore the results in light of them.

Epidemiological data show a strong relationship between the use of illicit and licit drugs and self-harm. For example, the use of tobacco and 'drinking to get drunk' increases the odds of selfharm by 3.33 and 3.27 respectively (Martin et al., 2010) and the use of cannabis by 2.10 (personal communication Martin 2012). Among the males in the current study, the use of substances as a coping mechanism rather than substance use per se remained a significant predictor even when cannabis use and tobacco use were added to the model. For women, while substance use as a coping mechanism was significant in the mediation model, it was no longer significant when tobacco use was included as a covariate. 
The data also showed marked gender differences in the pattern of relationships between the measures of alcohol use, coping and self-harm. Most notable was the non-significant relationship between alcohol use and self-harm in females at both waves. Gender differences in alcohol consumption have been described as a universal phenomenon, although the reasons underlying this are largely unexplained (Holmila \& Raitasalo, 2005). Gender stereotypes persist such that drinking, heavy drinking and drunkenness are regarded as masculine behaviours (de Visser \& McDonnell, 2011). Therefore, the use of alcohol or other substances as a means of coping may be less culturally sanctioned for women than men.

Another explanation may be the active nature of substance use as a coping mechanism. NolenHoeksema, Stice, Wade and Bahon (2007) argue that children are taught different coping mechanisms with girls directed towards helpless, passive coping styles such as rumination, and males to more active coping styles such as distraction. The current data reflected this assertion, with women having significantly higher rumination scores than men (not reported in results). These authors also illustrate that ruminative behaviours are predictive of substance use and binge eating, which in this paper is considered a form of self-harm (Nolen-Hoeksema et al., 2007).

The model that best explains the data suggests that rumination precedes subsequent depressed mood. This mood occurs concurrently with the use of substances to cope, presumably with the mood and the rumination that fed it. These then predict engaging in self-harm behaviours. As mentioned, self-harm has been proposed as a way to escape self-awareness (Heatherton \& Baumeister, 1991; Nolen-Hoeksema et al., 2007). It may be that individuals ruminate and experience the worsened mood and increased self-awareness associated with it. They may then attempt to cope by using substances, and when this is not effective, they engage in self-harm to escape and to regulate their emotions. Such an explanation is fully consistent with the pattern of associations found for the men in our sample, although among women the mediating effect of substance use as a coping mechanism was not robust. Again, this could be due to the gender differences in coping styles with rumination being more commonly employed by females. What is 
needed now is an exploration of the possible circular relationship where the thoughts and emotions about the self-harm then feed back into the ruminative process. As mentioned, self-harm and substance use behaviours may elicit significant guilt and shame, which is further negative content to fill ruminations. Further examination of specific emotions (e.g. sadness, guilt and shame) in this model would provide further insight.

Most data on adult self-harm reveal no gender differences, although in adolescents the prevalence is typically greater in females (Fliege et al., 2009). In this sample, the prevalence was greater in males than females. This may be an idiosyncrasy relating to the methods specified in the self-harm questions. Alternatively, this sample had a high proportion of people $(\approx 40 \%)$ with an undergraduate or higher degree. Whilst this is consistent with the local population, it is considerably greater than the Australian average (23.7\%) (Australian Bureau of Statistics, 2011) and higher educational attainment was associated with self-harm.

\section{Clinical Implications}

These findings have implications for clinical practice in their demonstration of the complex inter-relationship of various emotion regulation strategies. Psychological interventions, regardless of their orientation, strive to replace maladaptive coping strategies with effective coping strategies. Clients may be employing multiple, maladaptive emotion regulation strategies and to ensure optimal outcomes practitioners must assess for this, and actively address each of these behaviours. Combating a client's self-harm behaviour may only serve to exacerbate their reliance on substance use or using cognitive therapy to reduce ruminations may paradoxically intensify a client's drive to regulate their emotions through self-harm behaviours. Effective therapy will require provision of a variety of adaptive strategies for clients to employ to reduce the likelihood that they will fall back upon those that are more damaging. The strong association between self-harm and sexual abuse / trauma in women also make this a vital area for assessment with clients.

\section{Limitations}


Even though rumination was a lagged variable (i.e. collected at wave 2), causation still cannot be asserted. Furthermore, the remaining variables were all measured at wave 3, so it is plausible that self-harm behaviour leads to increased depression, anxiety or coping through the use of substances rather than resulting from them. Demonstrating causation would be very difficult due to the inability to, or ethical risk of manipulating substance use, self-harm or rumination to observe changes in the other variables. Further, the current model only accounted for a quarter of the variance in self-harm. However, it has previously been noted that self-harm is an "overdetermined" behaviour and thus may serve multiple functions simultaneously for an individual, with more than one conceptual model applying and multiple proximal and distal events precipitating an instance of self-harm (Suyemoto, 1998). In addition, only the presence or absence of three forms of self-harm was assessed, with no evaluation of the frequency, severity or intent of these actions. We further acknowledge that our sample of Australian adults, while representative of the geographic region from which it was drawn, was likely to be of mainly European origin. Self-harm may manifest through different patterns of behaviour in different cultures, and be subject to different perceptions and constraints. Self-harm may also be particularly prevalent in minority groups (Bhui, McKenzie, \& Rasul, 2007; Skegg, Nada-Raja, Dickinson, Paul, \& Williams, 2003): increased odds of self-harm among those reporting bisexual orientation have been reported for this cohort (Moller, Tait, \& Byrne, 2012b). Understanding the factors that precipitate and maintain self-harm in these diverse groups should be a research priority.

\section{$\underline{\text { Acknowledgements }}$}

We thank Kaarin Anstey, Anthony Jorm, Bryan Rodgers, Trish Jacomb, Karen Maxwell and the PATH interviewing team for their contribution to the PATH Through Life Project. 


\section{$\underline{\text { References }}$}

Aldao, A., \& Nolen-Hoeksema, S. (2012). Specificity of cognitive emotion regulation strategies: A transdiagnostic examination. Behaviour Research and Therapy, 48, 974-983.

Aldao, A., Nolen-Hoeksema, S., \& Schweizer, S. (2010). Emotion-regulation strategies across psychopathology: A meta-analytic review. Clinical Psychology Review, 30(2), 217-237.

Anstey, K.J., Christensen, H., Butterworth, P., Easteal, S., Mackinnon, A., Jacomb, T., et al. (2011). Cohort Profile: The PATH through life project. International Journal of Epidemiology, 1-10.

Australian Bureau of Statistics. (2011). Education and Work, Australia, May 2011. Canberra: ABS.

Axelrod, S.R., Perepletchikova, F., Holtzman, K., \& Sinha, R. (2011). Emotion regulation and substance use frequency in women with substance dependence and borderline personality disorder receiving dialectical behavior therapy. American Journal of Drug and Alcohol Abuse, 37, 37-42.

Babor, T.F., Higgins-Biddle, J.C., Saunders, J.B., \& Monteriro, M.G. (2001). AUDIT The Alcohol Use Disorders Identification Test: Guidelines for Use in Primary Health Care, 2nd Ed. Geneva: World Health Organization.

Baron, R.M., \& Kenny, D.A. (1986). The moderator-mediator variable distinction in social psychological research: Conceptual, strategic and statistical considerations. Journal of Personality and Social Psychology, 51, 1173-1182.

Bhui, K., McKenzie, K., \& Rasul, F. (2007). Rates, risk factors and methods of self harm among minority ethnic groups in the UK: A systematic review. BMC Public Health, 7, e336.

Brinker, J.K., \& Dozois, D.J.A. (2009). Ruminative thought style and depressed mood. Journal of Clinical Psychology, 65, 1-19. 
Carver, C.S. (1997). You want to measure coping but your protocol's too long: Consider the Brief COPE. International Journal of Behavioral Medicine, 4(1), 92-100.

Clark, C., Caldwell, T., Power, C., \& Stansfeld, S. (2010). Does the influence of childhood adversity on psychopathology persist across the lifecourse? A 45-year prospective epidemiologic study. Annals of Epidemiology, 20(5), 385-394.

Davis, R.N., \& Nolen-Hoeksema, S. (2000). Cognitive inflexibility among ruminators and nonruminators. Cognitive Behaviour Therapy, 24(6), 699-711.

de Visser, R.O., \& McDonnell, E.J. (2011). 'That's OK. He's a guy': A mixed-methods study of gender double-standards for alcohol use. Psychology and Health, 27(5), 618-639.

Fairweather, A.K., Anstey, K.J., Rodgers, B., Jorm, A.F., \& Christensen, H. (2007). Age and gender differences among Australian suicide ideators: prevalence and correlates. Journal of Nervous and Mental Disease, 195(2), 130-136.

Feldman, M.D. (1988). The challenge of self-mutilation: A review. Comprehensive Psychiatry, 29(3), 252-269.

Fliege, H., Lee, J.-R., Grimm, A., \& Klapp, B.F. (2009). Risk factors and correlates of deliberate self-harm behavior: A systematic review. Journal of Psychosomatic Research, 66(6), 477 493.

Goldberg, D., Bridges, K., Duncan-Jones, P., \& Grayson, D. (1988). Detecting anxiety and depression in general medical settings. British Medical Journal, 297, 897-899.

Gratz, K.L. (2003). Risk factors for and functions of deliberate self-harm: An empirical and conceptual review. Clinical Psychology Science and Practice, 10(2), 192 - 205.

Gross, J.J. (1999). Emotion regulation: Past, present, future. Cognition and Emotion, 13, 551 573.

Hayes, A.F. (2012). Indirect. Retrieved 11 Oct 2012, from http://afhayes.com/spss-sas-and-mplusmacros-and-code.html (Archived by Webcite at URL http://www.webcitation.org/6BKG573rg) 
Hayes, A.F. (2013). Some Frequently Asked Questions. Retrieved 2 April 2013, from http://www.afhayes.com/macrofaq.html (Archived by WebCite ${ }^{\circledR}$ at http://www.webcitation.org/6FZWG74h1)

Heatherton, T.F., \& Baumeister, R.F. (1991). Binge eating as escape from self-awareness. Psychological Bulletin, 110, 86-108.

Holmila, M., \& Raitasalo, K. (2005). Gender differences in drinking: why do they still exist? Addiction, 100(12), 1763-1769.

Khantzian, E.J. (1997). The self-medication hypothesis of substance use disorders: A reconsideration of recent applications. Harvard Review of Psychiatry, 4, $231-244$.

Klonsky, E.D. (2007). The functions of deliberate self-injury: a review of the evidence. Clinical Psychology Review, 27(2), 226-239.

Kratofil, P.H., Baberg, H.T., \& Dimsdale, J.E. (1996). Self-mutilation and severe self-injurious behavior associated with amphetamine psychosis. General Hospital Psychiatry, 18(2), 117 120.

Martin, G., Swannell, S.V., Hazell, P.L., Harrison, J.E., \& Taylor, A.W. (2010). Self-injury in Australia: a community survey. Medical Journal of Australia, 193(9), 506-510.

Meneses-Gaya, C.d., Zuardi, A.W., Loureiro, S.R., \& Crippa, J.A.S. (2009). Alcohol Use Disorders Identification Test (AUDIT): an updated systematic review of psychometric properties. Psychology \& Neuroscience (Online), 2, 83-97.

Moller, C.I., Tait, R.J., \& Byrne, D.G. (2012a). Deliberate self-harm, substance use and negative affect in non-clinical samples: A systematic review. Substance Abuse (accepted 15.06.12).

Moller, C.I., Tait, R.J., \& Byrne, D.G. (2012b). Self-harm, substance use and psychological distress in the Australian general population. Addiction, 13-17-2012.

Moore, E.A., Green, M.J., \& Carr, V.J. (2012). Comorbid personality traits in schizophrenia: Prevalence and clinical characteristics. Journal of Psychiatric Research, 46(3), 353-359. 
Nada-Raja, S., Skegg, K., Langley, J., Morrison, D., \& Sowerby, P. (2004). Self-harmful behaviors in a population-based sample of young adults. Suicide and Life-Threatening Behavior, 34, 177-186.

Nolen-Hoeksema, S. (2004). Gender differences in risk factors and consequences for alcohol use and problems. Clinical Psychology Review, 24, 981-1010.

Nolen-Hoeksema, S., \& Harrell, Z.A. (2002). Rumination, depression, and alcohol use: Tests of gender differences. Journal of Cognitive Psychotherapy: An International Quarterly, 16(4), 391-403.

Nolen-Hoeksema, S., \& Morrow, J. (1991). A prospective study of depression and posttraumatic stress symptoms after a natural disaster: The 1989 Loma Prieta Earthquake. . Journal of Personality and Social Psychology, 61(1), 115-121.

Nolen-Hoeksema, S., Stice, E., Wade, E., \& Bohon, C. (2007). Reciprocal relations between rumination and bulimic, substance abuse, and depressive symptoms in female adolescents. Journal of Abnormal Psychology, 116, 198 - 207.

Preacher, K.J., \& Hayes, A.F. (2008). Asymptotic and resampling strategies for assessing and comparing indirect effects in multiple mediator models. Behavior Research Methods, 40(3), 879-891.

Rosenman, S., \& Rodgers, B. (2004). Childhood adversity in an Australian population. Social Psychiatry and Psychiatric Epidemiology, 39(9), 695-702.

Selby, E.A., Anestis, M.D., \& Joiner, T.E. (2008). Understanding the relationship between emotional and behavioral dysregulation: Emotional cascades. Behaviour Research and Therapy, 46(5), 593-611.

Skegg, K., Nada-Raja, S., Dickinson, N., Paul, C., \& Williams, S. (2003). Sexual orientation and self-harm in men and women. American Journal of Psychiatry, 160, 541-546.

Suyemoto, K.L. (1998). The functions of self-mutilation. Clinical Psychology Review, 18(5), 531554. 
World Health Organization. (1986). International Classification of Diseases and Health Related Problems: 9th Revision: Clinical Modification. Geneva: WHO.

World Health Organization. (1993). Composite International Diagnostic Interview. Geneva: WHO. 
Table 1 Descriptive characteristics of no self-harm and any self-harm groups at wave 3

\begin{tabular}{|c|c|c|c|c|}
\hline Variable & & \multirow{2}{*}{$\begin{array}{c}\text { No self-harm } \\
(\mathbf{N}=\mathbf{3 8 3 9})\end{array}$} & \multirow{2}{*}{$\begin{array}{c}\begin{array}{c}\text { Any self-harm } \\
(\mathbf{N}=\mathbf{2 8 7})\end{array} \\
124(43)\end{array}$} & Statistic \\
\hline Gender & female $\mathrm{n}(\%)$ & & & $\chi^{2} 11.7$ (1) $p=.001$ \\
\hline & male $\mathrm{n}(\%)$ & $1779(46)$ & $163(57)$ & \\
\hline Age group & 20 's n $(\%)$ & $1748(45)$ & $206(72)$ & $\chi^{2} 73.8(2) p<.001$ \\
\hline & 40 's n $(\%)$ & $2091(55)$ & $81(28)$ & \\
\hline Marital status & married n $(\%)$ & $2245(59)$ & $122(43)$ & $\chi^{2} 44.9(2) p<.001$ \\
\hline \multicolumn{2}{|c|}{ separated/ divorced n $(\%)$} & $509(13)$ & $30(11)$ & \\
\hline \multicolumn{2}{|c|}{ never married n $(\%)$} & $1079(28)$ & $134(47)$ & \\
\hline \multirow[t]{2}{*}{ Employment } & full time $\mathrm{n}(\%)$ & $2938(77)$ & $212(74)$ & $\chi^{2} 8.3(3) p=.040$ \\
\hline & part-time n $(\%)$ & $540(14)$ & $34(12)$ & \\
\hline \multicolumn{2}{|c|}{ unemployed/ looking n (\%) } & $91 \quad(2)$ & $12(4)$ & \\
\hline \multicolumn{2}{|c|}{ not in labour force $\mathrm{n}(\%)$} & $268 \quad(7)$ & $29(10)$ & \\
\hline \multirow[t]{3}{*}{ Education } & secondary n (\%) & $589(15)$ & $49(17)$ & $\chi^{2} 8.3(4)$ \\
\hline & certificate n $(\%)$ & $1198(31)$ & $98(34)$ & \\
\hline & diploma n $(\%)$ & $407(11)$ & $32(11)$ & \\
\hline \multicolumn{2}{|c|}{ undergraduate degree $\mathrm{n}(\%)$} & $867(23)$ & $44(16)$ & \\
\hline \multicolumn{2}{|c|}{ higher degree $\mathrm{n}(\%)$} & $774(20)$ & $64(22)$ & \\
\hline \multicolumn{2}{|c|}{ Sexual abuse by parent no $\mathrm{n}(\%)$} & $3783(99)$ & $277(97)$ & $\chi^{2} 6.78(1) p=009$ \\
\hline & yes n $(\%)$ & $41 \quad(1)$ & $8(3)$ & \\
\hline \multirow[t]{3}{*}{ Smoking } & never $\mathrm{n}(\%)$ & $2199(57)$ & $121(43)$ & $\chi^{2} 59.3(2) p<.001$ \\
\hline & former $\mathrm{n}(\%)$ & $1030(27)$ & $69(24)$ & \\
\hline & current $\mathrm{n}(\%)$ & $605(16)$ & $95(33)$ & \\
\hline \multirow[t]{3}{*}{ Cannabis } & never $\mathrm{n}(\%)$ & $1481(39)$ & $62(22)$ & $\chi^{2} 73.1(2) p<.001$ \\
\hline & former $\mathrm{n}(\%)$ & $1978(52)$ & $153(54)$ & \\
\hline & current n (\%) & $367(10)$ & $69(24)$ & \\
\hline AUDIT score & mean $(\mathrm{SD})$ & $3.9(5.28)$ & $3.6(5.85)$ & t $3.80(2145) p<.001$ \\
\hline Depression & mean $(\mathrm{SD})$ & $2.5(2.36)$ & $4.6(2.68)$ & t 9.62 (2179) $p<.001$ \\
\hline Anxiety & mean $(\mathrm{SD})$ & $3.7(2.70)$ & $5.9(2.53)$ & t $8.81(2181) p<.001$ \\
\hline Rumination & mean $(\mathrm{SD})$ & $8.3(5.59)$ & $13.8(6.69)$ & $\begin{array}{r}\mathrm{t} 10.65(2172) \\
p<.001\end{array}$ \\
\hline Financial strain & median (IQR) & $0(0,0)$ & $0(0,0)$ & MW $112550 p<.001$ \\
\hline Major trauma & median (IQR) & $1(0,2)$ & $2(1,3)$ & MW $82736 p<.001$ \\
\hline COPE-S & median (IQR) & $0(0,2)$ & $1(0,3)$ & MW $98931 p<.001$ \\
\hline
\end{tabular}

AUDIT $=$ Alcohol Use Disorders Identification Test: COPE-S= Brief COPE substance use scale: IQR = inter quartile range: $\mathrm{SD}=$ standard deviation: $\mathrm{MW}=$ Mann-Whitney U test (maximum value 1 101793: no difference in ranks 550896.5) 
Table 2 Zero-order correlation coefficients for key measures at wave 2 and wave 3: Males are below the diagonal, females are above.

\begin{tabular}{|c|c|c|c|c|c|c|c|c|c|c|}
\hline Measure & 1 & 2 & 3 & 4 & 5 & 6 & 7 & 8 & 9 & 10 \\
\hline 1 Depression w3 & & .71 & .61 & .20 & .08 & .52 & .47 & .44 & .11 & .18 \\
\hline 2 Anxiety w3 & .71 & & .56 & .22 & .12 & .47 & .56 & .43 & .14 & .18 \\
\hline 3 Rumination w3 & .62 & .56 & & .26 & .12 & .45 & .43 & .62 & .13 & .19 \\
\hline 4 COPE-S w3 & .25 & .26 & .25 & & .60 & .17 & .18 & .21 & $.47 *$ & .10 \\
\hline 5 AUDIT w3 & .10 & .13 & .09 & .60 & & .10 & .12 & .10 & $.70 * * *$ & $.04 *$ \\
\hline 6 Depression w2 & .55 & .48 & .48 & .20 & .11 & & .74 & $.59 * *$ & .14 & .13 \\
\hline 7 Anxiety w2 & .50 & .55 & .44 & .18 & .10 & .74 & & .54 & .15 & .16 \\
\hline 8 Rumination w2 & .49 & .44 & .63 & .20 & .10 & $.65 * *$ & .55 & & .16 & .16 \\
\hline 9 AUDIT w2 & .09 & .11 & .09 & $.53 *$ & $.76^{* * * *}$ & .13 & .10 & .14 & & $.03 *$ \\
\hline 10 Self-harm w3 & .23 & .21 & .23 & .14 & $.11 *$ & .17 & .18 & .20 & $.10 *$ & \\
\hline
\end{tabular}

Anxiety = Goldberg Anxiety Scale: AUDIT = Alcohol Use Disorders Identification Test: COPE-S = COPE substance use subscale: Depression = Goldberg Depression Scale: Rumination = 10-item Rumination Responses Scale: $w 2=$ wave 2, w3 = wave 3:

Correlation coefficients are Pearson's $r$ except those with self-harm which are Spearman's $\rho$ :

All bivariate correlations values above .05 are statistically significant at $p<.001$ :

Significant gender differences in correlations shown in bold, assessed via Fisher's r-to-z transformation: * $p<.05, * * p<.01, * * * p<.001$. 
Table 3 Bootstrapped, bias-corrected 95\% confidence intervals and contrasts by gender for rumination

on self-harm via mediators ('ab' path)

\begin{tabular}{|c|c|c|c|c|c|c|}
\hline & Effect & S.E & $95 \% \mathrm{CI}$ & Effect & S.E & $95 \% \mathrm{CI}$ \\
\hline & \multicolumn{3}{|c|}{ Males } & \multicolumn{3}{|c|}{ Females } \\
\hline Total & .022 & .006 & $.011, .032$ & .050 & .009 & $.032, .067$ \\
\hline w3 depression & .019 & .005 & $.008, .029$ & .026 & .010 & $.005, .045$ \\
\hline w3 COPE-S & .003 & .002 & $.001, .008$ & .006 & .003 & $-.001, .012$ \\
\hline w3 anxiety & & & & .019 & .010 & $-.003, .038$ \\
\hline \multicolumn{7}{|l|}{ Contrasts } \\
\hline Depression- COPE-S & .016 & .006 & $.004, .027$ & .020 & .011 & $-.003, .040$ \\
\hline Depression - anxiety & & & & .007 & .018 & $-.031, .042$ \\
\hline Anxiety - COPE-S & & & & .013 & .011 & $-.010, .034$ \\
\hline
\end{tabular}

Anxiety $=$ Goldberg Anxiety Scale: COPE-S = COPE substance use subscale: Depression = Goldberg Depression: w2 = wave 2, w3 = wave 3: anxiety included only in the female model 
Figure 1a (upper) males \& figure 1b (lower) females: Simultaneous entry mediation analysis of relationships among rumination, depression, anxiety, use of substances for coping and self-harm. Values are unstandardized regression coefficients after adjusting for control variables with standardized regression coefficients shown in brackets. 


\section{$\underline{\text { Males }}$}

\begin{tabular}{|lcr|}
\hline Controls: & coefficient & $p$ value \\
age group & -.07 & $<.001$ \\
cannabis use & .03 & $\mathrm{~ns}$ \\
tobacco use & .09 & $\mathrm{~ns}$ \\
education & .15 & .041 \\
financial strain & .30 & $\mathrm{~ns}$ \\
major trauma & .04 & $\mathrm{~ns}$ \\
childhood & -16.9 & $\mathrm{~ns}$ \\
sexual abuse & & \\
w3 anxiety & .05 & $\mathrm{~ns}$ \\
\hline
\end{tabular}

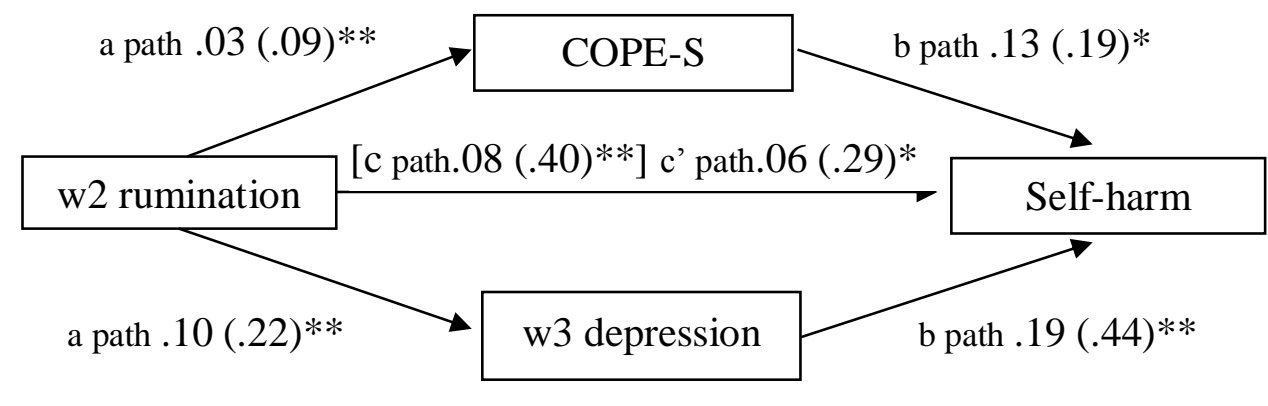

Wave $2 \uparrow \quad$ Wave $3 \uparrow \quad$ Wave $3 \uparrow$

\section{$\underline{\text { Females }}$}

\begin{tabular}{|lcr|}
\hline Controls: & coefficient & $p$ value \\
age group & -.03 & .007 \\
cannabis use & .40 & $\mathrm{~ns}$ \\
tobacco use & .59 & .017 \\
education & .07 & $\mathrm{~ns}$ \\
financial strain & .02 & $\mathrm{~ns}$ \\
major trauma & .14 & .008 \\
childhood & 1.00 & .042 \\
sexual abuse & & \\
\hline
\end{tabular}

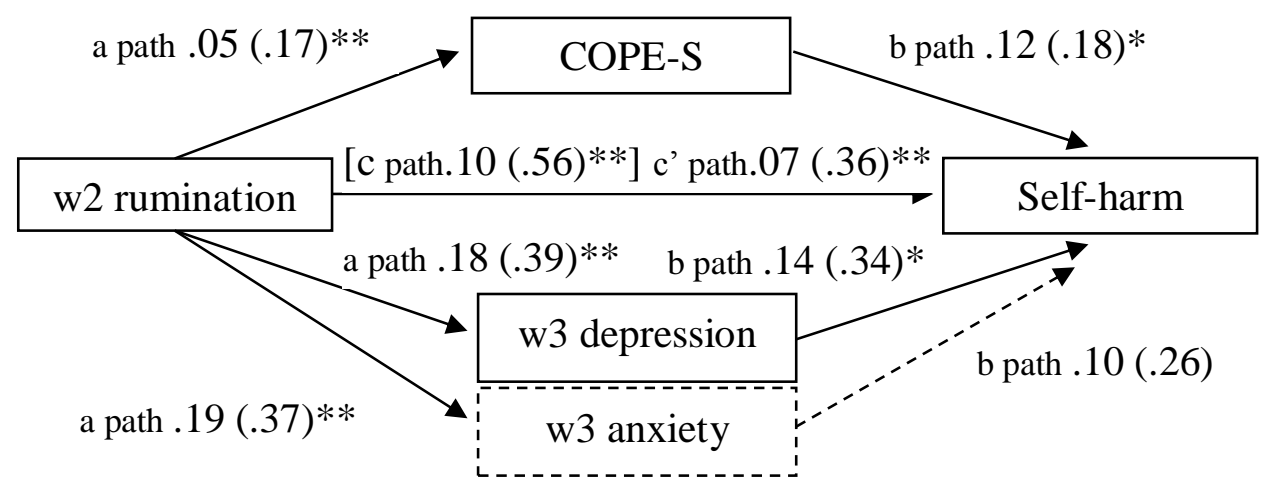

Wave $2 \uparrow \quad$ Wave $3 \uparrow \quad$ Wave $3 \uparrow$

$\mathrm{w} 2=$ wave $2: \mathrm{w} 3=$ wave $3: * p<.05: * * p<.001$ 